\title{
Prevalence of occupational hazards in patients with different types of epithelial sinonasal cancers*
}

\author{
Matteo Bonzini',2, Paolo Battaglia33, Davide Parassoni², Michela Casà2, \\ Nadia Facchinetti², Mario Turri-Zanoni ${ }^{3}$, Rossana Borchini², \\ Paolo Castelnuovo ${ }^{1,3}$, Marco M. Ferrario ${ }^{1,2}$ \\ 'Epidemiology and Preventive Medicine Research Centre, University of Insubria, Varese, Italy \\ 2 Occupational Medicine Units, Ospedale di Circolo-Fondazione Macchi, Varese, Italy \\ ${ }^{3}$ Department of Otorhinolaryngology, University of Insubria, Varese, Italy
}

Rhinology 51: 000-000, 2013 DOl:10.4193/Rhino11.228 *Received for publication: October 24, 2011

Accepted: October 11, 2012

\section{Summary}

Background: Occupational exposure to carcinogens contributes greatly to the etiology of sinonasal cancer (SNC), but the role of different risk factors in determining different histological subtypes is disputed.

Methodology: All consecutive surgical epithelial SNC cases (case-series study) underwent a systematic occupational medicine examination to determine previous exposure to a wide range of work-related chemical hazards.

Results: We investigated 65 SNC cases including intestinal-type adenocarcinoma [ITAC] squamous-cell carcinoma [SCC], and others. Occupational exposure was recognized for 39 cases. Occupational exposures were sensibly more frequent among ITAC than among SCC or other histotypes. Occupational exposure in ITAC cases was to leather or wood dust only, while among nonITAC cases, we recognised exposure to formaldehyde, solvents and metal fumes. A high proportion of SNC with occupational exposure originated in the ethmoidal epithelium.

Conclusion: In our case-series of SNC, a very high frequency of previous occupational exposure to carcinogens was detected, suggesting that occupational hazards may be associated to the aetiopathogenesis, primarily for ITAC, but also for other histotypes. Besides leather or wood, other chemical agents must be recognized as occupational risk factors.

Key words: paranasal sinus tumours, case-series study, wood, leather, occupational cancer

\section{Introduction}

Malignant tumours of the nose and paranasal sinuses (SNC) are uncommon neoplasms (incidence lower than one per 100,000 in the more developed countries) ${ }^{(1)}$. Epithelial tumours represent over two/third of the SNC and, among them, the most common histotypes are adenocarcinoma and squamous cell carcinoma (SCC) ${ }^{(2)}$ with European studies showing a frequency of adenocarcinoma ${ }^{(3-5)}$ higher than that reported in the corresponding
Northern American studies ${ }^{(6,7)}$. Other less common sinonasal epithelial histologies are adenoid cystic cancer (ACC) and undifferentiated carcinoma (SNUC).

It is very important to locate the primary site of the tumours properly, since the frequency of various anatomical sites of onset differs considerably between the various types of sinonasal cancer: the most common histotype in the maxillary sinus is 
SCC, while adenocarcinomas, and in particular the intestinal type (ITAC) are more frequent in the ethmoidal sinus.

The nasal cavity is the most common portal of entry and a wellknown target site for a wide range of pollutants and chemically induced carcinogenicity ${ }^{(8)}$. Occupational factors are responsible for a huge proportion of epithelial SNC besides other established congenital or acquired risk factors such as previous radiotherapy in the region and tobacco smoking ${ }^{(9)}$, chromosomal and genetically determined alterations ${ }^{(10,11)}$, inverted papilloma ${ }^{(12)}$. Occupational risk factors that have been related with a higher incidence of SNC include wood dust ${ }^{(13)}$, leather dust ${ }^{(14)}$, nickel compounds and hexavalent chromium ${ }^{(15)}$, formaldehyde and other solvents ${ }^{(2,16)}$ and polycyclic aromatic hydrocarbons (PAHs) (17).

Occupational epidemiological studies have shown an increased risk of SNC also in workers employed in leather tanning ${ }^{(18)}$, production of isopropyl acid ${ }^{(19)}$ and among welders ${ }^{(20)}$.

Some epidemiological studies seem to indicate a different effect of various occupational factors in the different anatomical sites ${ }^{(21,22)}$ but a clear relationship between histotypes, anatomical site and occupational exposures has not been established clearly because it was only possible to exactly determine the site of onset of the disease in just a few studies.

To this end, Bimbi et al., (23) in a recent study from a large case record of patients who underwent cranio-facial resection in Italy, affirmed that the ethmoid was the only anatomical site affected by adenocarcinoma induced by wood or leather dust exposure. The authors declared that "no exposure at all was reported by any of the 250 patients with malignant sinonasal neoplasm originating in sites other than ethmoid", but they focused only on wood and leather dust and did not consider other established occupational factors. Therefore the effect of metals, solvent or other less common occupational factors on different anatomical sites has yet to be properly defined. Moreover, the aetiological role of occupational risk factors in sinonasal tumours different from ITAC needs to be better quantified.

To quantify the prevalence of all recognized occupational risk factors in inducing epithelial sinonasal malignant tumours, we systematically investigated (with a multidisciplinary approach in which surgeons and occupational physicians shared their complementary know-how) a large series of surgical cases in which the histology and the site of onset of the disease was clearly determined.

\section{Materials and methods}

\section{Subjects}

The eligible population was composed of 73 subjects over 30 years of age (51 males and 22 females) with a histological diagnosis of epithelial SNC. These patients were followed between February 2010 and August 2011 by the multidisciplinary postoperative care group at the Otorhinolaryngologycal Department of the University of Insubria, Varese (Italy). Before their inclusion, all histological diagnoses were independently reviewed by two pathologists who assigned concordant results in all cases.

A total of 65 (89\% of the eligible population) subjects were enrolled in the study and underwent a wide-ranging occupational physician examination. The occupational physician was blind to the histology and anatomical site of the disease onset. All the patients enrolled gave their informed consent to participate in this survey. The remaining 8 subjects were excluded because they either refused the occupational interview or they were too compromised health wise and/or cognitively impaired (in details: 5 ITAC cases, 2 ACC, 1 SCC; 7 of them arose from ethmoidal epithelium).

\section{Clinical and pathological management}

Clinical data, surgical reports, pre- and post-operative images, and follow-up information of patients with malignant tumours in the sinonasal tract and the adjacent skull base who underwent endoscopic resection at the Department of Otorhinolaryn-

Table 1. General characteristics of enrolled patients divided according to the different histotypes.

\begin{tabular}{|c|c|c|c|c|c|c|c|}
\hline Histotype & $\begin{array}{l}\text { No of } \\
\text { cases }\end{array}$ & $\mathbf{N}^{\circ}$ & (\%) & \multicolumn{2}{|c|}{ Smokers (former or current) } & \multicolumn{2}{|c|}{$\begin{array}{c}\text { Site of onset } \\
\text { (\% Ethmoidal cases) }\end{array}$} \\
\hline ITAC & 39 & 5 & (13) & 21 & (54) & 37 & $(95)$ \\
\hline $\begin{array}{l}\text { Other } \\
\text { adenocarcinoma }\end{array}$ & 4 & 3 & $(75)$ & 1 & (25) & 3 & $(75)$ \\
\hline SCC & 13 & 8 & $(62)$ & 6 & (46) & 9 & $(69)$ \\
\hline ACC & 4 & 2 & $(50)$ & 4 & $(100)$ & 1 & $(25)$ \\
\hline SNUC & 5 & 1 & $(20)$ & 4 & (80) & 5 & (100) \\
\hline All cases & 65 & 19 & (29) & 36 & (55) & 55 & $(85)$ \\
\hline
\end{tabular}


Table 2. Cases with occupational exposure: site of onset, duration of exposure and latency period divided according to the different histotypes.

\begin{tabular}{|c|c|c|c|c|c|c|}
\hline Histotype & & $\mathbf{N}$ & Cases & $\%$ of total & $\begin{array}{c}\text { Occupational exposure, years } \\
\text { Mean (min-max) }\end{array}$ & $\begin{array}{l}\text { Latency } \\
\text { Mean (min-max) }\end{array}$ \\
\hline \multirow[t]{2}{*}{ ITAC } & Ethmoidal & 37 & 32 & 87 & $24(4-50)$ & $52(30-72)$ \\
\hline & Not Ethmoidal & 2 & 2 & 100 & $43(40-45)$ & $45(40-49)$ \\
\hline \multirow[t]{2}{*}{$\begin{array}{l}\text { Other } \\
\text { adenocarcinoma }\end{array}$} & Ethmoidal & 3 & 0 & - & - & - \\
\hline & Not Ethmoidal & 1 & 0 & - & - & - \\
\hline \multirow[t]{2}{*}{ SCC } & Ethmoidal & 9 & 2 & 22 & $46(9-37)$ & $51(50-51)$ \\
\hline & Not Ethmoidal & 4 & 0 & - & - & - \\
\hline \multirow[t]{2}{*}{ ACC } & Ethmoidal & 1 & 1 & 100 & $11(11)$ & $44(44)$ \\
\hline & Not Ethmoidal & 3 & 1 & 33 & $6(6)$ & $43(43)$ \\
\hline \multirow[t]{2}{*}{ SNUC } & Ethmoidal & 5 & 1 & 33 & $37(37)$ & $41(41)$ \\
\hline & Not Ethmoidal & 0 & & - & - & - \\
\hline All cases & & 65 & 39 & 60 & $26(4-50)$ & $51(30-72)$ \\
\hline
\end{tabular}

Table 3. Retrieved carcinogens agents in our study population (cases with occupational exposure only), stratifying different histhotypes. The numbers reported in Table refer to each single episode of exposure, consequently the total number of exposures could outnumber the cases (because of multiple exposures).

\begin{tabular}{|c|c|c|c|c|c|c|c|c|c|}
\hline Histotype & Wood dust & Cork & Leather dust & Leather tanning & Formaldehyde & Solvents & PAHs & Metal fumes & Chromium \\
\hline ITAC & 15 & 2 & 16 & 1 & 0 & 0 & 0 & 0 & 0 \\
\hline $\begin{array}{l}\text { Other } \\
\text { adenocarcinoma }\end{array}$ & 0 & 0 & 0 & 0 & 0 & 0 & 0 & 0 & 0 \\
\hline SCC & 1 & 0 & 0 & 0 & 1 & 1 & 0 & 0 & 0 \\
\hline $\mathrm{ACC}$ & 0 & 0 & 1 & 0 & 0 & 0 & 0 & 0 & 1 \\
\hline SNUC & 0 & 0 & 0 & 0 & 0 & 0 & 1 & 1 & 0 \\
\hline
\end{tabular}

gology were retrieved from a dedicated database.

All the patients enrolled in the study underwent endoscopic resection of the tumour through an exclusive endonasal approach (EEA) or cranio-endoscopic approach (CEA) (24), either alone or in combination with neoadjuvant or adjuvant radiotherapy or chemotherapy.

The surgical excision was tailored to the extension of the disease and to the specific tumour characteristics (histology, site of origin and proximity to critical areas), since the aim was to achieve radical resection of the lesion.

To properly localize the site of origin of the tumour, we integrated pre-operative information, obtained from gadolinium enhancement Magnetic Resonance Imaging [MRI] and endoscopic endonasal examination, with intra-operative findings obtained during careful endonasal endoscopic disassembling of the lesion and mapping of all the sinonasal sub-sites with multiple biopsies sent for frozen section. In all cases, the primary site of the tumour was identified as the structure most involved.

\section{Occupational physician examination}

All enrolled cases were systematically evaluated by an occupational physician who also referred to the specific guidelines developed by the National Registry for SNC cases ${ }^{(25)}$. Detailed information was collected about patient characteristics, extraprofessional risk factors such as smoking habits or previous head and neck diseases, complete occupational history, leisure activities, environmental or domestic exposures. When a potential occupational exposure emerged (i.e. employment in wood industry, leather industry, or welding) focused and detailed investigations to quantify any possible occupational exposure to carcinogenic agents were conducted.

In details, we systematically evaluated and quantified (in years) possible or sure exposures to wood and leather dust, leather tanning, cork, solvents, formaldehyde, PAHs, metal fumes, diesel 
exhaust, nickel, chromium, arsenic or pesticide.

\section{Statistical analysis}

We performed formal statistical tests to highlight differences between different histotypes (comparing ITAC cases with all other tumours). We used the Wilcoxon rank-sum test to analyse continuous variables (i.e. latency period and duration of exposure) and the Fisher's exact test for dichotomous variables (presence of a previous exposure to carcinogens: any exposure vs. no exposure or wood/leather exposure vs. any other carcinogens). Data analysis was performed using STATA statistical software (version 11.0 Stata Corp, Austin, TX, USA) and a p-value $<0.05$, two sides, was assumed as statistically significant.

\section{Results}

After 18 months of collaboration in the multidisciplinary postoperative care group, we enrolled and investigated 65 patients affected by epithelial SNC. Mean age at diagnosis was 62 years (minimum 34, maximum 85 ). Twenty seven (42\%) patients were from the Lombardy Region (where our tertiary care centre is located) while the remaining $58 \%$ declared to live outside the Region.

Main characteristics of enrolled cases, dividing different SNC histotypes are shown in Table 1.

As reported in other European studies, our population was mainly composed of subject with ITAC histotype (39/65 cases, $60 \%)$, followed by SCC (13/65 cases, 20\%). Only 29\% (19/65) of the cases were female, with the proportion of male being higher $(71 \%, 46 / 65)$, especially between ITAC (34/39 cases, $87 \%)$. Moreover, 36 patients declared to be current or former smokers. Regarding the site of disease onset, we observed a very high proportion of ethmoidal cases (55/65 cases, $85 \%)$, especially within the ITAC group (37/39).

Results of the occupational medicine evaluation are reported in Table 2. Considering all investigated cases, the proportion of cases that showed a previous occupational exposure was $60 \%$. We observed a very important proportion of cases with documented exposure to a known occupational carcinogenic agent among the ITAC cases ( 32 out of 37 for ethmoidal cases and both of the 2 non-ethmoidal cases). As expected, other histotypes showed a lower proportion of cases exposed to occupational hazards: in detail, occupational exposure was found in 5 out of 26 non-ITAC tumours and in 34 out of 39 ITAC cases (19\% vs. $87 \%$; Fisher's test $p$-value $<0.001)$. It is worth noting that we documented occupational exposure to established carcinogens for all different histotypes (with the exception of 'other adenocarcinoma' that represented only 4 cases).

For all histotypes different from ITAC, we observed a higher proportion of cases with occupational exposure among the tumours that originated in the ethmoidal epithelium.
The mean duration of exposure for all cases with occupational exposure (total cases $=39$ ) was 26 years $(S D=14.9$ range $=4-50$, Median $=23$ Inter Quartile Range $=10-37$ ), and the mean observed latency period was $51(S D=10.1$, range $30-72$, median $=51$, Inter Quartile Range $=44$ - 61). No significant differences regarding duration of exposure or latency appeared (Wilcoxon rank sum tests: $p<0.05$ ) comparing ITAC cases with other different histotypes.

Detailed information about occupational exposures that were documented in our study population is reported in Table 3. In all ITAC cases it was possible to detect previous exposure to wood and leather dust. In detail, we observed 15 patients who reported exposure to hardwood dust, 2 cases were employed in the cork industry, 16 cases had been exposed to leather dust and one case was involved in the leather tanning process. Interestingly, no ITAC cases reported occupational exposure to carcinogens other than leather or wood.

Conversely, these factors were detected only in less than $50 \%$ of SCC and SNUC cases, who resulted to have been exposed to chemical agents like formaldehyde, solvents, $\mathrm{PAH}$, metal fumes (1 case each). Finally, 2 ACC cases had former exposure to leather dust and to chromium, respectively. In detail, the proportion of non-ITAC cases that showed previous exposure to carcinogens other than wood or leather out of the total number of cases with some previous occupational exposure was $71 \%$ (5 out of 7, vs. $0 \%$ observed among ITAC cases, Fisher's test $p<0.001$ ).

\section{Discussion}

Epithelial SNC are confirmed to be tumours with an extremely high proportion of cases showing a former previous exposure to established occupational carcinogens.

In cases of occupational cancer, the current legislation in most Western countries, including Italy, foresees precise responsibility for any clinician who should treat the case, to ensure occupational cases identification, protection and compensation ${ }^{(26)}$.

Our systematic evaluation of a large multidisciplinary case series in which the histology and the site of onset of the disease were clearly assessed, showed that the proportion of occupational carcinogens among the cases of epithelial SNC differs deeply in relation to the site onset of the disease and across various histotypes.

The proportion of cases with occupational exposure resulted to be particularly high for ITAC, where $87 \%$ of the enrolled cases showed a former exposure to leather or hardwood dusts (and we found another subject with documented extraprofessional exposure to hardwood dust).

Other exposures, besides leather and wood, were often revealed when investigating SNC cases different from ITAC. Exposure to metals fumes, solvent or PAHs are common occupational conditions distributed more than wood and leather across occu- 
pational groups, and have been recognized capable of causing epithelial cancers in other anatomical sites (i.e. lung and upper respiratory tract) as well. Epidemiological studies that quantified the proportion of cases with former exposure to those agents in different sites (i.e. lungs) showed results that were comparable with those we observed ${ }^{(13,15,17)}$. Therefore, a systematic evaluation of their presence in the complete occupational history of each SNC case appears necessary, particularly in cases of epithelial SNC different from ITAC.

Results ensuing from our case series showed, as reported in other previous epidemiological studies ${ }^{(23)}$, that occupational cases are often characterized by a period of exposure sometimes lasting only a few years and by a latency period that is often very long. These conditions make the identification and the evaluation of the role of occupational exposures very challenging. Thus a multidisciplinary approach such as the one we followed in this study appears to be the most appropriate for recognizing a causal relationship. Compared with others case-series, our population appeared to be composed of a high proportion of males and of adenocarcinomas; this reflects on one hand, the typical distribution of European cases ${ }^{(3,23,27)}$, but on the other it could be also a direct consequence of the relatively high prevalence of wood and leather industry in Italy.

Another important factor emerging from our investigation is the particularly high proportion of ethmoidal tumours observed among cases with recorded previous occupational exposure. This result is worthy of further confirmation, also because many previous studies did not perform a systematic evaluation of the site of onset of the disease, and it is concordant with what was reported in the largest surgical case-series published ${ }^{(23)}$, supporting the hypothesis of a direct role of carcinogenic dust in the site of impact with the epithelium. In fact, a previous study showed that the ethmoid is the site of first contact in the respiratory tract with coarse particles such as wood and leather dusts ${ }^{(13)}$.

The major drawback of our study is that we based our investigation on cases only (no control group). Thus, no concrete conclusions on the causative nature of the observed exposure could be drawn. But the primary aim of our study was not so much to demonstrate the carcinogenic potential of some occupational hazard (which, however, has been already and definitely established in several well-conducted epidemiological studies $\left.{ }^{(13-17)}\right)$, but rather to underline the importance of a complete and multidisciplinary occupational evaluation of all SNC cases to properly highlight any possible relevant exposure to some established occupational hazard (not limiting investigation to wood and leather dusts alone) and in all different SNC subtypes.

Nevertheless, the data observed in the ITAC cases ( $87 \%$ with occupational exposure) are consistent with an important aetiological role of previous exposures to wood and leather dusts for at least two main reasons: first, the proportion of patients with previous wood and leather dust exposure among non-ITAC cases was 7.7\%, 2 a total of 26). Moreover, according to the 1991 Italian census data ${ }^{(28,29)}$, the number of workers employed in wood (or furniture) and in leather (including tanning) industries is substantially stable over time and was 186,000 and 243,500, respectively, in that year). Considering a total Italian population of people aged over 35 years at around 30 million (1991 data), this kind of worker constitutes less than $2 \%$ of the total population. Even considering the possible mobility of workers across occupational sectors during their working life, it is reasonable to estimate the proportion of subjects with former occupational exposure to wood or leather at less than $5 \%$ in our country.

Given the increased risk of ethmoidal adenocarcinoma among wood workers, some researchers have suggested the necessity for a screening protocol for early detection of occupational cancers ${ }^{(30)}$, being, according to their experience, a sinonasal endoscopic examination is the best tool in this respect. Nevertheless, even if the large proportion of cases with occupational exposures may justify preventive measures, we believe that the high latency observed in our and in other studies (as well as the fact that epithelial SNC remains a very rare cancer that affects only less than $1 \%$ of exposed subjects) would make impractical and not cost-effective such a large and invasive screening campaign on exposed workers.

A preventive approach based on educating the workers and informing them how to minimize exposure, stressing the importance of the correct use of environmental and personal protective equipment, appears to be more effective. These measures of primary prevention should be always associated with specific training for workers, as well as for occupational (and family) physicians, aimed to recognize even many years after exposure ceased, symptoms of SNC onset. In fact, the prognosis for SNC is nowadays still negatively influenced by delayed diagnosis, mainly caused by the non-specificity of early symptoms.

In conclusion, we confirmed that SNC cases are characterized by a very frequent exposure to occupational carcinogens; in view of this a multidisciplinary approach establishing primary preventive measures, early diagnosis and proper recognition of occupational cases appears to be mandatory for comprehensive patient care and support public health.

\section{Acknowledgements}

Authors were supported in the case ascertainment procedure and in data collection by Lombardy Sino-Nasal Registry, which collects all incident cases of SNC from the Lombardy region.

\section{Authorship contribution}

$\mathrm{MB}$ wrote the paper and chaired evaluation of the cases; $\mathrm{PB}$ and 
DP contributed in writing the paper and case collection; MC and NF contributed to case evaluation; MTZ contributed to recruitment of the cases and their evaluation; PC supervised case evaluation and contributed in carrying out the study and in writing the paper; MMF designed the study and supervised it.

\section{Conflict of interest}

The authors declare that they have no conflicting interests.

\section{References}

1. Curado MP, Edwards B, Shin HR, et al. Cance Incidence in Five Continents, Vol. IX IARC Scientific Publications No. 160, Lyon, IARC, 2007

2. d'Errico A, Pasian S, Baratti A, et al. A casecontrol study on occupational risk factors for sino-nasal cancer. Occup Environ Med. 2009; 66: 448-455.

3. Lund VJ, Howard DJ, Wei WI, et al. Craniofacial resection for tumors of the nasal cavity and paranasal sinuses: a 17 years experience. Head Neck. 1998; 20: 97-105

4. Wax MK, Yun KJ, Wetmore SJ, et al. Adenocarcinoma of the ethmoid sinus. Head Neck 1995; 17: 303-311.

5. Saunders SH, Ruff T. Adenocarcinoma of the para-nasal sinuses. J Laryngol Otol. 1976; 2 157-166.

6. Donald PJ. Complications in skull base surgery for malignancy. Laryngoscope. 1999; 109: 1959-1966

7. Gandour-Edwards R, Donald PJ, Boggan JE. Surgical pathology of the skull: a 7 year based experience. Skull Base Surg. 1998; 8 : 191-194.

8. Calderón-Garcidueñas L, Delgado R, Calderón-Garcidueñas A, et al. Malignant neoplasms of the nasal cavity and paranasal sinuses: a series of 256 patients in Mexico City and Monterrey. Is air pollution the missing link? Otolaryngol Head Neck Surg. 2000 122: 499-508.

9. 't Mannetje A, Kogevinas M, Luce $D$, et al Sinonasal Cancer, Occupation and Tobacco Smoking in European Women and Men. Am J Ind Med. 1999; 36: 101-107.

10. Zhu K, Levine RS, Brann EA, et al. Casecontrol study evaluating the homogeneity and heterogeneity of risk factors between sinonasal and nasopharyngeal cancers. Int Cancer. 2002; 99: 119-123.

11. Shimizu H, Hozawa J, et al. Chronic sinusitis and woodworking as risk factors for cancer of the maxillary sinus in northeast Japan. Laryngoscope. 1989; 99: 58-61.

12. Mirza S, Bradley PJ, et al. Sinonasal inverted papillomas: recurrence, and synchronous and metachronous malignancy. J Laryngol Otol. 2007; 121: 857-864.

13. International Agency for Research on Cancer. IARC monographs on the evaluation of carcinogenic risks to humans. Wood dust and formaldehyde. Lyon, France: IARC,
1995; 62.

14. Straif $K$, Benbrahim-Tallaa L, Baan R, et al. WHO International Agency for Research on Cancer Monograph Working Group: A review of human carcinogens-part C: metals, arsenic, dusts and fibres. Lancet Oncol. 2009: 10: 453-454

15. International Agency for Research on Cancer. IARC monographs on the evaluation of carcinogenic risks to humans. Chromium, Nickel and Welding. Lyon, France: IARC, 1990; 49.

16. International Agency for research on Cancer. IARC Monographs on the Evaluation of Carcinogenic Risks to Humans: Formaldehyde, 2-Butoxyethano and 1-tert-Butoxypropan-2-ol. Lyon, France: IARC, 2006; 88 .

17. International Agency for Research on Cancer. IARC monographs on the evaluation of carcinogenic risk to humans. Some Non-heterocyclic Polycyclic Aromatic Hydrocarbons and Some Related Exposures. Lyon, France: IARC, 2010: 92.

18. Battista G, Comba P, Orsi D, et al. Nasal cancer in leather workers: an occupational disease. J Cancer Res Clin Oncol. 1995; 121: 1-6.

19. International Agency for Research on Cancer. IARC monographs on the evaluation of carcinogenic risks to humans. Supplement 7 (1987) Overall Evaluation of Carcinogenicity: An Updating of IARC Monographs Volume 1 to 42 Lyon, France: IARC.

20. Hernberg S, Westerholm P, Schultz-Larsen K, et al. (1983) Nasal and sinonasal cancer. Connection with occupational exposures in Denmark, Finland and Sweden. Scand J Work Environ Health. 1983; 9: 315-326.

21. Luce D, Leclerc A, Bégin D, et al. Sinonasa cancer and occupational exposure: a pooled analysis of 12 case-control studies. Cancer causes control. 2002; 13: 147-157.

22. Leclerc A, Luce D, Demers Paul A, et al. Sinonasal cancer and occupation. Results from the reanalysis of twelve case-control studies. Am J Ind Med. 1997; 31: 153-165.

23. Bimbi G, Squadrelli Saraceno M, Riccio $S$, et al. Adenocarcinoma of ethmoid sinus: an occupational disease. Acta Otorhinolaryngol Ital. 2004; 24: 199-203.

24. Nicolai $P$, Battaglia $P$, Bignami $M$, et al. Endoscopic surgery for malignant tumors of the sinonasal tract and adjacent skull base: a 10-year experience. Am J Rhinology. 2008;
22: 308-316.

25. Marinaccio A, Binazzi A, Gorini G, et al Guidelines for the Sino-nasal Cancer National Register (ReNaTuNS) [Manuale operativo per la definizione di procedure e standard diagnostici e anamnestici per la rilevazione, a livello regionale, dei casi $\mathrm{d}$ tumore dei seni nasali e paranasali e attivazione del Registro Nazionale ReNaTuNS]. ISPESL publications Roma, 2008, available on line at http://www.ispesl.it/dml/ leo/download/LineeGuidaReNaTuNS.pdf [Italian]

26. Decreto del Presidente della Repubblica Italiana del 30 Luglio 1965 n. 1124 [Italian]

27. Roux FX, Behm E, Page $P$, et al. Adenocarcinomas of the ethmoid sinuses. Epidemiological data. Ann Otolaryngol Chir Cervicofac 2002: 119: 271-280.

28. ISTAT, 8th general census of industry and services, 2001. Available online at http:// www.istat.it/it/archivio/26939.

29. ISTAT [Popolazione per classi di età quinquennali, sesso, indicatori di vecchiaia e dipendenza strutturale per i censimenti 1861-2001 e 2009]. ISTAT publications [Italian] Available online at: http://seriestoriche.istat.it

30. De Gabory L, Conso F, Krief P, et al. Is ethmoidal adenocarcinoma screening in employees exposed to wood dust justified? Rev Laryngol Otol Rhinol (Bord). 2008; 129: 219-226.

Matteo Bonzini, MD MPH

Epidemiology and Preventive Medici-

ne Research Centre

University of Insubria

Ospedale di Circolo

Viale Borri 57

21100 Varese

Italy

Tel: +39-33-227 0693

Fax : +39-33-227 0698

E-mail: matteo.bonzini@uninsubria.it 